\title{
EDITORIAL
}

\section{El índice de niebla y la escritura científica}

\author{
The fog index and scientific writing
}

Los géneros literarios grosso modo son el épico, el lírico, el dramático y el didáctico. Estos a su vez se dividen subgéneros que le dan más aún un carácter particular a cada obra (1). Por ejemplo, entre los subgéneros didácticos se encuentran la oratoria, la historia, la biografía, el ensayo, etc. (2). Este último, es definido por Pérez (3) como "un escrito en prosa que expone sin rigor sistemático, pero con hondura y sensibilidad, una interpretación personal sobre cualquier tema, sea filosófico, histórico, literario, científico, etc.".

Tratando de clasificar de manera irreverente y ligera en qué género o subgénero podría clasificarse la escritura de artículos científicos, pensamos que quizás encajarían en el ensayo. No obstante, en nuestra experiencia como editores y autores de artículos científicos, consideramos que se nos olvida justamente que los artículos científicos no son obras literarias y escribimos más de la cuenta en muchas ocasiones, lo cual trae consecuencias negativas tanto para el escrito mismo como para los lectores. Entonces, si cada género literario tiene su propia finalidad, la de los artículos científicos es la de informar de manera clara, expositiva y argumentativa los resultados de una investigación (2).

Reconocemos que nosotros como autores de artículos científicos, en reiteradas ocasiones, no observamos algunas reglas gramaticales, lo que dificulta la comprensión del manuscrito por parte de los lectores, así como su traducción a otro idioma. En ese sentido, en nuestra labor editorial en la Rev. MVZ Cordoba se vela por la utilización de palabras comunes en el español internacional, con el fin de que podamos entendernos desde México hasta la Patagonia y en España. Además, es conveniente emplear palabras cuyo origen sea el latín para que los lectores no hispanohablantes puedan entender vocablos sin dificultad y para facilitar la traducción, lo cual es uno de los objetivos de la Rev. MVZ Cordoba. La escritura científica debe ser precisa para que el lector comprenda de manera exacta el significado de las palabras; por tanto, el lenguaje utilizado debe ser el denotativo, es decir, debe ser especieespecífico para hacer alusión a términos de las ciencias biomédicas y no el connotativo que está destinado para los géneros literarios. Sabemos también que cada autor tiene su propio estilo, pero se debe escribir de una manera sencilla, clara y directa, evitando la utilización de adornos literarios y de ambigüedades.

Si bien no existe una fórmula mágica que nos ayude a escribir (tarea nada fácil) someter nuestro escrito al cálculo del índice de niebla puede ser útil. El índice de niebla de Gunning (4), es una medida de la legibilidad de un escrito que se utiliza en lingüística. El índice se basa en dos indicadores: la longitud de las frases y de las palabras. Aunque el índice fue creado para el inglés y no para el español, puede ser un buen ejercicio aplicarlo a nuestros escritos para tratar de mejorarlos.

Para que el lector calcule el índice de niebla, debe seleccionar un fragmento de 100 palabras de su escrito sin omitir ninguna frase. Asimismo debe calcular el promedio de la longitud de 
las frases dividiendo el número de palabras totales entre el número de frases del fragmento, contabilizar las palabras con tres o más sílabas (palabras complejas), no incluir nombres propios o palabras compuestas, sumar el promedio de longitud de las frases y el porcentaje de palabras complejas y multiplicar el resultado por 0.4. Un índice de niebla ideal deber estar entre 6 y 11 . Si el resultado le da valores más altos, el lector debería revisar su escrito y tratar de simplificarlo. Pero si las cuentas no le dan, no se preocupe, en internet existen varios sitios gratis en donde se pueden hacer todos estos ejercicios automáticamente, así como las aclaraciones y ajustes del caso $(5,6)$.

Creemos, entonces, que el cálculo del índice niebla, es un recurso que tenemos los escritores de artículos científicos para evaluar la redacción de nuestros propios manuscritos. Esperamos que lo utilicen y buena suerte.

\section{Marco González T. M.Sc. Salim Mattar V. Ph.D.}

\section{REFERENCIAS}

1. Maestro JG. Crítica de los géneros literarios en el Quijote. Idea y concepto de género en la investigación literaria. Vigo, España: Editorial Academia del Hispanismo; 2009. ISBN 978-84-96915-41-1

2. Bibliotecas virtuales. [sitio web en Internet]. Los géneros literarios. [consultado Octubre de 2013]. URL Disponible en: http://www. bibliotecasvirtuales.com/biblioteca/articulos/ literatura.asp.

3. Pérez H. Comprensión y producción de textos educativos. Bogotá, Colombia: Cooperativa Editorial Magisterio; 2006.
4. Antoja RF. Comunicación: lenguaje y niebla. Rev Lab Clin 2009; 2(4):153154. URL Disponible en: http://zl.elsevier. es/es/revista/revista-del-laboratorioclinico-282/articulo/comunicacion-lenguajeniebla-13143088

5. Ovares Barquero F, Rubí Barquero J. Variación del índice de niebla usando un corpus obtenido a partir de los libros digitalizados por Google. UNICIENCIA 2010; 24(1):133-141.

6. Gunning Fog Index. [sitio web en Internet]. [consultada Octubre de 2013]. URL Disponible en: http://gunning-fog-index.com/index. html 